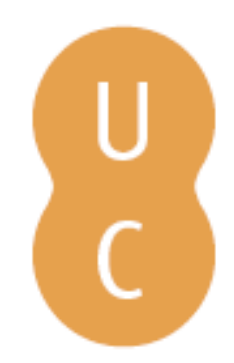

\title{
nombalina
}

\section{O silencioso coro no Hipólito euripidiano do Thíasos}

Autor(es): $\quad$ Carvalho, Ana Seiça

Publicado por: Centro de Estudos Clássicos e Humanísticos da Universidade de

URL

persistente: URI:http://hdl.handle.net/10316.2/30120

DOI: $\quad$ DOI:http://dx.doi.org/10.14195/978-989-721-010-5_17

Accessed : $\quad$ 26-Apr-2023 15:38:22

A navegação consulta e descarregamento dos títulos inseridos nas Bibliotecas Digitais UC Digitalis, UC Pombalina e UC Impactum, pressupõem a aceitação plena e sem reservas dos Termos e Condições de Uso destas Bibliotecas Digitais, disponíveis em https://digitalis.uc.pt/pt-pt/termos.

Conforme exposto nos referidos Termos e Condições de Uso, o descarregamento de títulos de acesso restrito requer uma licença válida de autorização devendo o utilizador aceder ao(s) documento(s) a partir de um endereço de IP da instituição detentora da supramencionada licença.

Ao utilizador é apenas permitido o descarregamento para uso pessoal, pelo que o emprego do(s) título(s) descarregado(s) para outro fim, designadamente comercial, carece de autorização do respetivo autor ou editor da obra.

Na medida em que todas as obras da UC Digitalis se encontram protegidas pelo Código do Direito de Autor e Direitos Conexos e demais legislação aplicável, toda a cópia, parcial ou total, deste documento, nos casos em que é legalmente admitida, deverá conter ou fazer-se acompanhar por este aviso.

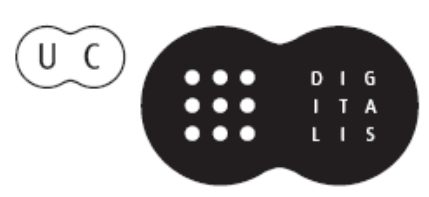




\section{Hipólito e Fedra}

\section{nos caminhos de um mito}

Carlos A. Martins de Jesus, Claudio Castro Filho, José Ribeiro Ferreira (coords.) 


\title{
O SILENCIOSO CORO NO HIPÓLITO EURIPIDIANO do Thíasos
}

\author{
Ana Seiça Carvalho \\ Universidade de Coimbra \\ "Elle se grise du goût de l'impossible, le seul alcool \\ qui sert toujours de base à tous les mélanges du malheur"
}

(M. Yourcenar 1974: 33)

Foi num ano letivo bastante preenchido, 2009-2010, que o grupo Thíasos, cuja história remonta já a 1992, acolheu diversos elementos novos que viriam a integrar e desenvolver a encenação da tragédia em volta da qual surgiu o presente volume, o Hipólito de Eurípides. A escolha recaiu na segunda versão da peça, apresentada segundo os estudiosos em 428 a.C., a única preservada na íntegra e a que tem vindo a influenciar, até aos nossos dias, inúmeros autores. Não será demais dizer que esta peça (aliás, a tetralogia onde se inseria) terá honrado com um dos seus primeiros prémios de carreira aquele que foi considerado por Aristóteles “o mais trágico dos poetas" (Poética 1453 29-31a).

O mito do sofrimento de uma rainha, Fedra, casada com Teseu e apaixonada, por domínio da deusa Cípris, pelo seu próprio enteado viria, uma vez mais, a apaixonar dois jovens encenadores.

Numa primeira fase, em meados de setembro de 2009, o Thíasos começou por receber, da parte de Claudio Castro Filho, um estruturado workshop, que teve a duração de três semanas. Embora os inscritos fossem numerosos, devido sobretudo a incompatibilidades de horário, elementos houve que acabaram por desistir e não chegaram, por conseguinte, a desenvolver o seu trabalho como personagem. Acabámos, por isso, por ficar somente com quatro elementos femininos para o papel do Coro das supostas quinze mulheres de Trezena, incluindo já o Corifeu. Neste sentido, deveremos dar a mão à palmatória às palavras de D. Leão (2010: 13), quando alude ao "movimento potenciado, em especial no teatro grego, pela presença em cena da verdadeira moldura humana que é o coro - de doze, quinze, vinte e quatro elementos - e não a pálida e envergonhada aparição a que regra geral se vê reduzido em reposições modernas”. Não obstante, e pensamos ser um bom caminho a tomar futuramente, o trabalho semanal com um grupo mais reduzido permite um aprofundamento físico e psicológico do estudo de cada personagem, assim como o desenvolvimento de uma dinâmica mais íntegra e mais íntima, de certa forma, dos seus elementos. É certo também que algumas personagens, quer na tragédia quer na comédia, eram muitas vezes figurantes mudos ou mensageiros e acompanhantes que entravam em cena apenas uma vez. Nesse sentido, interessante deverá ser a tentativa de desdobramento de personagens, 
que permite ao ator testar a sua capacidade de encarnar duas ou mais figuras, em diferentes momentos da peça. Já para não referirmos o facto de, em termos logísticos, a mobilidade e a adaptação de um grupo pequeno e de natureza académica a certos espaços se tornam muito mais facilitadas.

\section{Propostas de encenação ao Hipólito de Eurípides}

A grande testemunha e poço de segredos da tragédia é, normalmente, a figura do Coro que, com a sua cumplicidade, se aproxima do protagonista sofredor. Este partilha, desta forma, as dores dos protagonistas como um alter ego $^{1}$. Com Eurípides, comparando-o a Sófocles, o Coro não possui já uma parte tão ativa na ação (cf. Aristóteles, Poética 1456a 27-28) e dir-se-ia que entre as intervenções das personagens e as do Coro não existe uma harmonia lógica, nem um fio coeso. As intervenções do Coro são, de certa forma, independentes, contudo não desprovidas de sentido.

No caso de Hipólito e dos momentos de silêncio seus característicos, o Coro é a personagem que, quase muda, aprecia todo o desenrolar da ação, partilhando os segredos que vai escutando, não só daquela a quem serve, Fedra, mas de igual forma do filho de Teseu. Tem razão, a este respeito, J. H. K. Chong-Gossard (2008: 156), para quem "there is still another signification of silence in Euripides, and that is the willingness to keep silent the secrets of others".

As coreutas entram em cena enquanto se afadigam com a preparação do leito daquela que se encontra enferma. E, como mulheres companheiras, questionam-se entre si qual a razão do padecimento da rainha, especulando ardentemente acerca do seu estado. No entanto, remetem-se ao silêncio com a chegada da Ama e da rainha (vv.170-175). Em silêncio permanece Fedra, até decidir, por meio da confissão à Ama e ao Coro, aliviar o seu sofrimento. E, no entanto, será tal confissão que lhe trará a morte.

Embora alterne entre o silêncio e o desvelar do segredo que consome Fedra, a Ama opta pelo não-silêncio na tentativa - assim pensamos - de salvar a sua senhora da paixão que a consome. Toma, por fim, a resolução de não mais esconder os sentimentos da rainha, revelando a Hipólito a paixão que por ele nutre a madrasta. No entanto, antes sequer de lhe narrar os acontecimentos que assombram a mente de Fedra, fá-lo proferir juramento e, desta forma, Hipólito ver-se-á impedido de se salvar, mais tarde, diante do pai e perante a tabuinha escrita por Fedra. E é o seu próprio silêncio, respeitador da promessa que fizera à Ama, que o condena à morte.

${ }^{1}$ Vd. J. H. K. Chong-Gossard 2008: 156: "it seems a Euripidean convention that choruses tend to avoid lengthy conversations with actors other than a single heroine or hero with whom they might share some rapport”. 
Teseu, que chega ao palácio e se depara com a terrível tragédia da morte da esposa, é um homem que se deixa levar pelas emoções, demonstrando uma atitude demasiado impulsiva: recusa-se a escutar as súplicas do filho e a voz mais racional do Coro (se não racional, por serem companheiras de Fedra, pelo menos conhecedora dos acontecimentos) e dá azo à sua cólera perante a tabuinha de acusações que julga verdadeiras e destruidoras da sua própria honra. O desejo de vingança da morte da mulher e da suposta tentativa de sedução de Hipólito levam-no a precipitar-se nas imprecações que profere.

Em silêncio se quedam, por último, as quinze mulheres de Trezena, ainda que compreendam a dor da rainha e partilhem com ela o estatuto de mulheres e mães. Escutam a longa rhesis de Fedra (vv. 374-431) e procuram dissuadi-la dos seus intentos de morte (v. 724), mas em vão. Assistem à tentativa da Ama de conduzir Hipólito no caminho do amor, jurando silêncio. $E$ é esse silêncio que lhe traz a morte (vv. 1060-1063). O Coro, velando o corpo de Fedra, descobre-o para que Teseu o veja. No entanto, mantém-se num mudo conluio com o cadáver e acaba por ocultar a verdade ${ }^{2}$, afirmando desconhecer as causas do suicídio da Rainha (vv. 804-816). Perante a maldição a que Teseu vota o filho, o Coro insurge-se, ainda que tenuemente (v. 891), mas logo se afasta para um canto do palco, quando os companheiros de Hipólito entram em cena ${ }^{3}$, proferindo doces palavras, que somente amenizam o seu estado de espírito intranquilo (Terceiro Estásimo, vv. 1104 sqq.). Eis que chega o Mensageiro e narra o triste fim de Hipólito, caído e de corpo despedaçado pelo carro que conduzia. O moribundo é trazido para o leito púrpura e o Coro entoa o último Estásimo, confirmando apenas em lágrimas quão indubitavelmente forte é a vontade de Cípris. A tragédia termina, após a cena ex machina de Ártemis, que apenas vem procurar apaziguar a ira de Teseu e restituir a honra do filho (vv. 1284-1311), com uma imagem de pietà no masculino: Teseu sentado no leito, com o filho caído e moribundo nos braços (imagem 4).

Em relação às duas divindades, Afrodite e Ártemis que, no original, são desde o início identificadas em cena por duas estátuas, o encenador decidiu não colocar nenhuma figuração plástica, mas apenas material humano: e sendo que as duas deusas são, em boa verdade, rivais e complementares, Afrodite,

${ }^{2}$ Vd.J.H. K. Chong-Gossard 2008: 156: "In the Hippolytus and Iphigenia in Tauris, this goes one step further and involves half-truths or lies".

${ }^{3} \mathrm{O}$ constante desencontro entre mundo feminino e mundo masculino foi uma clara opção desta encenação. A única personagem que contacta diretamente com o mundo oposto é a Ama, pois interage com Hipólito. O Corifeu, até certo ponto, também acaba por interagir com o Mensageiro que vem dar a notícia do acidente de Hipólito na praia, e com Teseu. Os silêncios na peça em questão são o ponto fulcral que une e separa, num só tempo, as personagens. A decisão entre falar e manter o silêncio domina o enredo do princípio ao fim, à exceção do Coro que, uma vez jurando não narrar nenhum dos acontecimentos, se mantém fiel à sua promessa. Cf. B. Knox 1979: 207-214, B. E. Goof 1990: 1-26. 
deusa do amor, Ártemis, deusa da caça e da virgindade ${ }^{4}$, interessante se tornou o efeito de ser a mesma atriz a representar ambos os papéis, no início, como Cípris, no final como Ártemis ex machina.

\section{Figurinos e sua relevância}

Os vestidos que as duas deusas envergam são semelhantes, variando apenas a cor - bordeau o de Afrodite, branco o de Ártemis -, feitos ambos de um tecido de penas. A sensualidade do primeiro, conseguida por um corte mais sensual, contrasta com a sobriedade do segundo, no pálido da sua cor e na sua maior discrição. Os dois cubos que desde o início se encontram em cena, um mais recuado, à direita do palco, o outro na boca de cena, à esquerda, são as estruturas onde as deusas se colocam e das quais se dirigem ao público e às personagens.

A primeira personagem a aparecer em cena é Afrodite, mas o encenador, neste caso, tomou como cena inicial a aparição de Fedra, sob uma luz de tons avermelhados, no intuito de abrir a peça com um prólogo coreográfico que, simbolicamente - no final há de perceber-se - resumisse o enredo. A rainha vem, de sensual e despojada camisa de dormir ${ }^{5}$, também ela vermelha, deixando colo e ombros nus, a dançar de olhar perdido, deitando-se e erguendo-se do leito - que domina a cena central - em gestos ora sensuais, ora desvairados. Nas mãos acaba por deter uma fita dourada que faz rodopiar à sua volta, lentamente, até se deixar cair, com a fita simbolicamente presa com dois laços em torno do seu pescoço, numa clara metáfora que deixa antever, em prolepse, a hora da asfixia e da morte.

Afrodite entra, de seguida, dominando a cena, pelo meio do público, envergando aos ombros um longo pano púrpura que arrasta pesadamente pelo chão. Principia a falar de costas voltadas, virando-se repentinamente e deixando cair o tecido das costas. Caminha sensualmente pelo palco, deita-se no leito onde Fedra se tinha anteriormente estendido amorosamente, e ameaça a sua vingança. $\mathrm{O}$ público, aqui, começa a compreender o seu ódio por Hipólito, devoto de Ártemis, e a tomar conhecimento do seu poder nos acontecimentos

${ }^{4}$ Uma virgindade oposta à assexualidade de Atena: Ártemis é virgem por decisão própria. Curioso como a uma virgem inviolável agrada no entanto a caça selvagem, brutal e sanguinária. Já para não referir o pormenor de Ártemis ser ora a protetora das mulheres grávidas e dos seus respetivos partos (cf. vv.163-167) ora a responsável pela morte das parturientes. Para um estudo mais aprofundado das divindades, vd. W. Burkert 1985: 149-156.

${ }_{5}^{5}$ Assim era a ideia do encenador, trazer a cena uma rainha que, embora mostrasse um semblante carregado e pálido, pois há três dias que não se alimentava, em claro protesto pelos seus sentimentos, não deixasse de ser uma mulher sensual e tomada por Eros, pelo desejo carnal. Além de que Fedra, não o esqueçamos, tem sobre si toda uma carga familiar de sensualidade, como bem exprime F. Lourenço no texto que incluiu neste livro. 
vindouros. Afrodite trará motivos de lágrimas e dor, destruindo Fedra e instrumentalizando a rainha para dar forma ao seu projeto de vingança (cf. M. C. Fialho 1996: 36). Afrodite, no original, não torna a aparecer, mas na presente encenação, silenciosamente, coloca-se sobre o cubo da direita do palco, de costas, altiva, como uma estátua. Como se se transformasse em estátua imóvel na presença de seres humanos. Voltará a caminhar sensualmente pelo palco quando, no início do Primeiro Estásimo, entregar nas mãos das coreutas as fitas que estas agitam nas suas danças frenéticas e sensuais, saindo em seguida.

Os vestidos com que se traja o Coro (imagens 5 e 6), à primeira vista pouco arqueológicos, de um branco creme, com um corte evasé muito rodado, permitem efeitos deslumbrantes com o andamento em palco e durante os movimentos frenéticos das danças. Compõem-se de duas partes, uma bordeau arroxeada e uma branca que cai por cima daquela largamente, embora ligeiramente mais curta para deixar antever a de baixo. Abaixo do peito, uma fita arroxeada e bordada a fio do mesmo tom, brilhante, igual à que remata a orla do decote, completam com um detalhe elegante o conjunto. Os cabelos, normalmente repuxados completamente atrás num apanhado simples, são colmatados com a colocação de uma fita dourada.

Ouvimos, de seguida, as vozes dos jovens Servos e de Hipólito correndo e principia a música. Nas primeiras atuações do grupo, entravam somente os Servos e Hipólito. A dado momento, tornou-se interessante aos olhos do encenador criar um paralelismo entre os dois mundos: entram, desta feita, Hipólito, os companheiros e as mulheres do Coro, mas nunca se cruzam nem se falam, pois os seus planos são opostos. As mulheres vêm em passo apressado e decidido, cada uma com o seu vaso grego pintado, dirigem-se ao rio que corria por detrás do palácio e aí lavam, com gestos dinâmicos e silenciosos, o enxoval branco da casa real.

A introdução da nova cena deveu-se, em boa verdade, a uma necessidade de adaptação ao espaço, muito diferente, claro está, do palco do Teatro Paulo Quintela, tradicional palco à italiana. A mudança incrementou as potencialidades e o enriquecimento da visualização da peça. Os dois níveis de palco improvisado - a 26 de junho de 2010, no Mosteiro de Santa Clara-a-Velha - influenciaram a ideia, aliada a um jogo cénico plástico de se criar uma cena paralela que, desde então, se tem vindo a repetir nas atuações, de que foi exemplo a de Vila Pouca de Aguiar, a 4 de setembro de $2009^{6}$.

\footnotetext{
${ }^{6}$ A entrada para o auditório da vila foi o palco do nosso espetáculo: na rampa de acesso, posicionaram-se os bancos que o Coro ocuparia, ao cimo dos degraus centrais colocou-se o leito de Fedra e nas restantes cenas as personagens evolucionavam na calçada defronte. Assim se criou a ideia das duas cenas paralelas: o mundo masculino num plano e os elementos do Coro a lavar a roupa no rio, de cada lado do pano púrpura deixado por Afrodite, no outro. A adaptação é sempre concebida no local em que a peça vai ser representada, ou seja, normalmente, poucas
} 
Mal os Servos terminam as suas oferendas à deusa Ártemis, o Mensageiro sensato dialoga com Hipólito a propósito da sua exagerada e antinatural virgindade, que o espectador sente como contrária à condição de ser humano. O drama desenrolar-se-á, a partir deste ponto, com a sucessão de silêncios e de revelações, que culminam na morte dos protagonistas, como bem entende W. Burkert (1985: 152): "in the experience of love the loved one and indeed the whole world appears transfigured (...) a tremendous power is revealed".

\section{Detalhes da encenação}

Duas cenas houve cuja encenação se arrastou ainda largos meses sem que soubéssemos com precisão o que fazer, quais os passos de dança, qual o movimento em palco e a atitude a tomar como personagem. Foram elas a cena do Primeiro Estásimo, que denominámos cena da loucura, cuja dança frenética com as fitas procurou criar um paralelismo com o prólogo coreográfico de Fedra. A música é acompanhada de movimentos circulares, ondulantes, passos desorientados e gestos de sensualidade corporal. Decidiu-se que Afrodite ficaria em palco, até distribuir as fitas luxuriantes pelas coreutas e sair em passo sensual pelo meio do Coro, que dança freneticamente. $\mathrm{O}$ ritmo frenético termina de rompante e as quatro mulheres, nesse instante, caem como estátuas, como se a possessão divina as abandonasse. A segunda cena que demorou igualmente a ser idealizada foi a chamada cena da bipnose, correspondente ao Segundo Estásimo. Por fim, surgiu um quadro convincente: perante uma música de cadência grave, hipnotizadas, as mulheres de Trezena caminham como que sonâmbulas pelo palco, antecipando a notícia do suicídio de Fedra, preferindo uma situação mais estável para as suas próprias vidas (vv. 733776). Nesta cena, foram utilizadas lâmpadas de LED, que a nossa designer de luzes, Chayanna Ferreira, nos aconselhou: pela primeira vez usadas em cena pelo Thíasos, a luz branca, misturada com os azulados dos projetores, resultou num efeito surpreendente, dir-se-ia quase fantasmagórico, coincidente com os versos euripidianos como os seguintes (vv. 768-771):

E transbordando de insuportável sofrimento atará às traves do quarto nupcial um laço pendente ajustando-o em torno do alvo pescoço.

horas antes da atuação, o que exige do encenador um trabalho de raciocínio rápido. Como atriz, gostei substancialmente da escolha do encenador para a cena da hipnose realizada no Claustro do Museu Machado de Castro, ao cimo da escadaria. 
É em tom monocórdico e cavo, "hipnótico", de braços estendidos ao longo do corpo, que o Coro entoa lentamente pelo palco o Segundo Estásimo. Os quatro elementos seguram o manto púrpura deixado no solo por Afrodite e com ele cobrem o leito de Fedra, segurando as pontas de forma a parecer uma portada que impede a visão do público. Uma particularidade importante nesta cena é o facto de, mal as quatro mulheres terminam, cada uma à vez, de entoar o excerto que lhes foi confiado, voltarem a repetir, desta vez em uníssono, a sua estrofe. O efeito é aterrador, resultando numa musicalidade desordenada de palavras diferentes, diferentes vozes, proferidas em uníssono mas desencontrado, em tom cavo e grave. O Coro repete as suas estrofes até se ouvir estridente o grito da Ama (v. 777), que anuncia o suicídio já aguardado da rainha.

Após o Segundo Estásimo e a entrada em cena de Teseu (Terceiro Episódio, v. 790), quando este pede para que as portas do palácio se abram (vv. 809-811), o Coro larga repentinamente o pano, destapando o leito, onde está já o corpo de Fedra estendido. A partir de então, horrorizado e choroso, o Coro observa com visível medo a desonra e a morte em catadupa que se abatem sobre o palácio: antecipa a reação impulsiva de Teseu à tabuinha (vv. 853-856) e procura acalmá-lo, levando-o a refletir nas imprecações que está prestes a proferir furiosamente contra o filho.

Quando Hipólito, moribundo, é trazido à presença do pai, o Coro, juntamente com os companheiros, entoa o Quarto Estásimo, com a conclusão do poder inquestionável de Cípris (vv. 1269-1281). Neste momento se optou por, num esforço de arqueologia, cantar em grego parte do estásimo; perdendo-se naturalmente em compreensão literal, a cena ganha, estamos em crer, pela criação de uma atmosfera fúnebre, intensificada pelo ritmo pesaroso dos versos cantados. Tudo isto não deixa de ser uma contradição consciente, na medida em que, na verdade, o que os dois coros nesse momento cantam, em tom lúgubre, é um hino a Afrodite, que realça os seus poderes de deusa do amor. Algo que, no limite, se revela coerente, já que todos perceberam, ao tempo, como foi essa deusa a responsável pela tragédia entretanto consumada.

A peça termina com Hipólito morrendo nos braços do pai. O Coro e os companheiros de caça ladeiam o seu leito de morte. No final, banhados por uma luz fraca, avermelhada de sangue, saem à vez os companheiros e os elementos do Coro, levando consigo os bancos e os cubos que haviam sido colocados no início, numa metáfora de descontrucção de um lar que foi destruído pelas mortes de entes queridos. A luz apaga-se lentamente sobre o quadro de pietà masculina Teseu e Hipólito, deixando o Coro patente uma derradeira mensagem (v. 1464), que "os ataques de choro hão-de prolongar-se".

Não querendo, de forma alguma, repetir tudo quanto já os meus colegas e outros intervenientes aqui referiram, valerá no entanto a pena acentuar a 
ideia de que, como grupo de teatro universitário, o Thíasos tem conhecido uma gradual e positiva evolução, o que constitui não só um grande motivo de orgulho, mas sobretudo um incentivo para continuar a trabalhar com vista a um aperfeiçoamento cada vez maior. 